\title{
MINAT INVESTASI DI KALANGAN MAHASISWA GENERASI MILENIAL DI SURAKARTA
}

\author{
Tri Ratna Pamikatsih, Ari Susanti \\ Sekolah Tinggi Ilmu Ekonomi Surakarta \\ E-mail: santisties@gmail.com
}

\begin{abstract}
This research aims to see how the influence of capital market knowledge and returns on student investment interest. This research was conducted using quantitative methods with sample size of 120 respondents. The analysis used is multiple linear regression analysis. The results of this research indicated that capital knowledge has a significant effect on student investment interest, When student understand about capital market knowledge deeply, it will increase the student interest on invetsment. Return also also has a significant effect on student investment interest. The level of profit offered by the capital market is the basis for student interest in investing
\end{abstract}

Keywords : Student Investment Interest, Capital Market Knowlegde, Return

\section{PENDAHULUAN}

Perkembangan sebuah negara dapat dipengaruhi oleh beberapa hal. Berkembangnya suatu pasar modal menjadi salah satu faktor yang menggambarkan hal tersebut. Perkembangan suatu pasar modal akan dilihat dari berapa banyak investasi yang berjalan disana. Ketika suatu pasar modal berkembang, menggambarkan bahwa perekonomian negara tersebut ikut berkembang. Perkembangan pasar modal ini tidak akan lepas dari yang namanya investor.

Investor merupakan komponen penting dalam pasar modal. Semakin banyak investor yang menanamkan modalnya di pasar modal, maka pasar modal di negara tersebut akan makin berkembang. Perkembangan pasar modal di Indonesia sendiri terus mengalami peningkatan, hal ini di lihat dari jumlah investor pasar modal yang tiap tahunnya terus mengalami peningkatan

Gambar 1. Jumlah Investor Pasar Modal di Indonesia

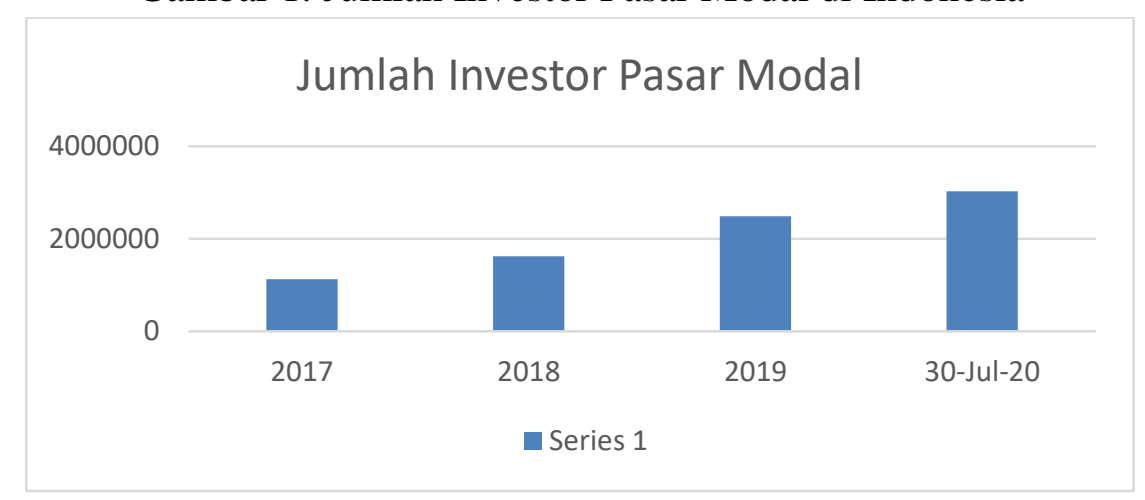

Sumber: KSEI News 
Menurut data yang diperoleh PT Kustodian Sentral Efek Indonesia (KSEI), demografi investor di Indonesia didominasi oleh generasi milenial. Generasi mileneal ini berusia antara 2031 tahun. Pada akhir 2019, ada sekitar 44,62 \% investor yang masuk dalam usia tersebut. Sehingga dapat disimpulakan bahwa minat berinvestasi di pasar modal terus mengalami peningkatan, khususnya generasi milenial. .

Mahasiswa merupakan salah satu dari sekian banyak generasi milenial yang ada. Mahasiswa mendapatkan banyak dorongan yang membuat minat mereka untuk untuk melakukan investasi di pasar modal menjadi lebih tinggi. Pengetahuan mengenai pasar modal yang diterima saat perkuliahan menjadi bekal dasar mereka untuk meningkatkan minat berinvestasi di pasar modal. Iming-iming keuntungan yang ditawarkan oleh pasar modal menjadi salah satu faktor yang membuat mahaswa semakin ingin berinvestasi. Berdasarkan data-data tersebut, maka penelitian akan apakah pengetahuan dasar mengenai pasar modal dan keuntungan atau return yang didapat berpengaruh terhadap minat generasi milenial, khiususnya mahasiswa untuk berinvestasi.

\section{Pengetahuan Investasi Pasar Modal}

Tandelilin (2010), pasar modal dapat dikatakan sebagai wadah yang mempertemukan antara mereka yang dana berlebih dan mereka yang membutuhkan. Jenis instrumen yang diperjual belikan adalah instrument jangka panjang, oleh karena itu ketika seseorang melakukan investasi disana, maka investasi yang mereka lakukan adalah investasi jangka panjang.

Dalam memilih salah sarana investasi yang tepat, salah satu faktor yang mendukung adalah pemahaman atau pengetahuan seseorang terhadap investasi. Latha (2016) menjelaskan bahwa pengetahuan investasi merupakan segala sesuatu yang berkaitan dengan penilaian investasi. Doddy dan Milah (2019) mengatakan bahwa seorang investor harus memiliki pemahaman mengenai investasi yang cukup untuk memilih investasi yang cocok dengan kebutuhannya dan dapat terhindar dari penipuan.

Menurut Susanto (2012), seorang calon investor harus memahami mengenai 3 (tiga) macam pengetahuan sebelum melakukan investasi. Pengetahuan yang pertama adalah pengetahuan mengenai investasi. Seorang calon investor harus mengerti mengenai bagaimana kebutuhan dan tujuan dari investasi yang mereka rencanakan. Pengetahuan yang kedua adalah pengetahuan mengenai risiko. Calon investor harus bisa mengerti risiko-risko apa saja yang akan dihadapo baik secara risiko mikro maupun risiko makro. Dan yang terakhir adalah pengetahuan menganai aliran kas, yang nantinya berkaitan dengan bagaimana mengelola aliran kas dalam periode tertentu.

Ketika seseorang memutuskan untuk berinvestasi pada pasar modal, maka penting bagi mereka untuk memahami pasar modal secara dalam. Tanpa pengetahuan akan investasi pasar modal yang cukup, maka mereka dalam memilih instrumen maupun melakukan transaksi akan mengalami banyak kendala.

\section{Return}

Return atau keuntungan menurut Devianti dkk (2017) merupakan timbal balik yang didapatkan seseorang terhadap investasi yang mereka keluarkan. Return yang didapatkan oleh tiap intrumen investasi memiliki perbedaan satu sama lain. Return tidak akan bisa lepas dari yang namanya risiko. 
High risk high return merupakan kalimat yang sering di terdengar di kalangan investor di pasar modal. Istilah ini menjelaskan bahwa ketika seorang investor menginginkan return yang tinggi, maka mereka harus mau menanggung risiko yang besar juga. Begitupun sebaliknya, apabila seorang investor lebih memilih mendapatkan keuntungan yang tidak terlalu banyak, maka risiko yang tanggung juga akan kecil.

Tingkat return juga tidak lepas dari yang namanya persepsi. Persepsi dari tiap investror akan berpengaruh terhadap tingkat risiko yang akan diambil. Usia dan tingkat pendidikan investor juga akan mempengaruhi, misalnya antara seorang pekerja dan mahasiswa memiliki persepsi yang berbeda mengenai return yang diharapkan. Trisnation (2017) menjelaskan bawah mahasiswa cenderung melakukan investasi dipasar modal dengan harapan mendapatkan return yang tinggi. Mereka berasumsi bahwa ketika melakukan investasi dipasar modal akan mendapatkan keuntungan yang tinggi pula. Pemahaman mereka mengenai return dan risiko yang dihadapi ketika di pasar modal menjadi salah satu faktor yang membuat mereka berminat berinvestasi di pasar modal.

\section{Minat Investasi}

Minat merupakan sebuah perasaan tertarik akan suatu hal. Perasaan ini akan membuat seseorang menjadi lebih condong untuk menaruh perhatian lebih kepada objek atau peristiwa tersebut. Marpaung (2009) menjelakan bahwa ketika seseorang telah munjukkan minta terhadap sesuatu, maka mereka akan mencoba untuk mendapatkannya. Mereka yang memiliki minat akan sesuatu akan lebih cenderung mencurahkan perhatiannya terhadap hal tersebut. Berbanding terbalik dengan seseorang yang tidak memiliki minat akan suatu hal, maka mereka tidak akan menunjukkan rasa perhatiannya, walaupun diberikan berbagai stimulan.

Nandar dkk (2018) menjelaskan bahwa ketika seseorang memiliki minat, maka akan berpengaruh terhadap apa yang mereka lakukan. Faktor yang menyebabkan hal ini terjadi adalah faktor inner urge. Faktor inner urge merupakan ransangan yang didapatkan seseorang yang berasal dari lingkungan sekitar. Adanya lingkungan yang mendukung kebutuhan seseorang, maka dengan mudah lingkungan tersebut menimbulkan minat. Ini juga yang terjadi ketika mahasiswa mendapatkan informasi dan pengetahuan mengenai investasi pasar modal lebih mendalam. Ketika mereka mendapatkan pengetahuan investasi pasar modal, maka minat akan investasi pasar modal akan lebih mudah muncul. Sehingga dapat dikatakan bahwa minat investasi adalah ketertarikan seseorang tarhadap aktivitas investasi, khususnya investasi pada pasar modal.

\section{Hipotesis}

Berdasarkan penjabaran kajian teori yang telah dilakukan, maka hipotesis yang diambil dalam penelitian ini antara lain:

$\mathrm{H}_{1}$ : Pengetahuan tentang investasi pasar modal berpengaruh positif dan signifikan terhadap minat investasi mahasiswa Surakarta

$\mathrm{H}_{2}$ : Return berpengaruh positif dan signifikan terhadap minat investasi mahasiswa Surakarta 




Gambar 1. Kerangka Penelitian

\section{METODE PENELITIAN}

Populasi yang digunakan dalam penelitian ini merupakan seluruh mahasiswa di perguruan tinggi swasta Surakarta, dengan menggunakan purposive sampling sebagai teknik pengambilan sample nya. Purposive sampling merupakan ini digunakan untuk menentukan sampel yang sesuai dengan kriteria penelitian. Dalam penelitian ini, kriteria yang ditentukan antara lain:

a. Mahasiswa yang usianya minimal 17 tahun. Usia ini merupakan usia dimana seseorang cenderung lebih mandiri, sehingga mereka bisa memutuskan dengan bijak mengenai keputusan apa yang harus mereka ambil.

b. Mahasiswa yang telah mendapatkan mata kuliah manajemen investasi pasar modal. Ketika mahasiswa mendapatkan mata kuliah tersebut, maka mereka akan lebih memahami mengenai pengetahuan investasi pasar modal lebih dalam

Berdasarkan kriteria yang telah ditentukan, maka kuisioner di bagikan kepada 120 mahasiswa. Teknik analisis yang digunakan dalam penelitian ini adalan teknik analisis kuantitatif. Teknik ini dilakukan dengan cara mengolah data menggunakan alat analisis SPSS versi 25.

\section{Definisi Operasional}

Pemilihan instrumen dalam penelitian ini adalah instrumen angket. Angket ini dibuat dengan menggunakan skala likert. Skala likert digunakan dengan alasan agar responden lebih memahami dari konteks pertanyaan. Instrumen yang ditanyakan dalam angket tersebut berjumlah 4 (empat) indikator untuk variabel $\mathrm{X}_{1}$ (pengetahuan investasi pasar modal), 5(lima) indikator untuk variabel $\mathrm{X}_{2}$ (return) dan 4 (empat) indikator untuk variabel $\mathrm{Y}$ (minat investasi).

Tabel 2. Variabel Penelitian

\begin{tabular}{|c|c|c|}
\hline Variabel & Keterangan & Indikator \\
\hline \multirow[t]{4}{*}{$\mathbf{X}_{1}$} & Pengetahuan Investasi Pasar & 1. Pemahaman tentang pasar modal \\
\hline & Modal & 2. Instrumen keuangan \\
\hline & & 3. Pengembalian \\
\hline & & 4. Prinsip investasi \\
\hline \multirow[t]{3}{*}{$\mathbf{X}_{2}$} & Return & 1. Daya tarik return \\
\hline & & 2. Jaminan \\
\hline & & 3. Prinsip keuntungan \\
\hline
\end{tabular}




\begin{tabular}{|c|c|c|}
\hline & & $\begin{array}{ll}\text { 4. } & \text { Peluang } \\
\text { 5. } & \text { Tujuan investasi }\end{array}$ \\
\hline $\mathbf{Y}$ & Minat Investasi & $\begin{array}{ll}\text { 1. } & \text { Ketersediaan informasi } \\
\text { 2. } & \text { Minat investasi } \\
\text { 3. } & \text { Kesadaran diri } \\
\text { 4. } & \text { Ketertarikan }\end{array}$ \\
\hline
\end{tabular}

\section{HASIL DAN PEMBAHASAN}

\subsection{Hasil penelitian}

\section{Validitas dan Reabilitas}

Pengujian validitas dilakukan untuk melihat apakah item pertanyaan yang sebar dapat diguanakan sebagai alat pengukur yang akurat. Berdasarkan uji validitas yang diujikan pada tiap variabel, maka didapatkan hasil sebagai berikut:

Tabel 3. Uji Validitas

\begin{tabular}{lcccc}
\hline \multicolumn{1}{c}{ Variabel } & Butir & Pearson Correlation & R Tabel & Pengujian \\
\hline Pengetahuan Investasi & 1 & 0,698 & 0,1797 & Valid \\
Pasar Modal $\left(\mathrm{X}_{1}\right)$ & 2 & 0,565 & 0,1797 & Valid \\
& 3 & 0,665 & 0,1797 & Valid \\
& 4 & 0,716 & 0,1797 & Valid \\
\hline Return $\left(\mathrm{X}_{2}\right)$ & 1 & 0,735 & 0,1797 & Valid \\
& 2 & 0,793 & 0,1797 & Valid \\
& 3 & 0,690 & 0,1797 & Valid \\
& 4 & 0,642 & 0,1797 & Valid \\
& 5 & 0,760 & 0,1797 & Valid \\
\hline Minat Investasi (Y) & 1 & 0,799 & 0,1797 & Valid \\
& 2 & 0,753 & 0,1797 & Valid \\
& 3 & 0,767 & 0,1797 & Valid \\
& 4 & 0,800 & 0,1797 & Valid
\end{tabular}

Sumber: Data Primer diolah, 2020

Berdasarkan hasil uji validitas pada tabel 2, maka tampak bahwa item pertanyaan dari variabel dinyatakan valid. Maka pengujian selanjutnya bisa dilakukan, yaitu pengujian reablititas. Uji reabilitas dilakukan untuk melihat konsistensi dari item pertanyaan yang sebelumnya sudah dinyatakan valid. 
Tabel 4. Uji Reabilitas

\begin{tabular}{lc}
\hline \multicolumn{1}{c}{ Variabel } & Cronbach's Alpha \\
\hline Pengetahuan Investasi Pasar Modal $\left(\mathbf{X}_{\mathbf{1}}\right)$ & 0,760 \\
\hline Return $\left(\mathbf{X}_{\mathbf{2}}\right)$ & 0,786 \\
\hline Minat Investasi $(\mathbf{Y})$ & 0,808
\end{tabular}

Sumber: Data Primer diolah, 2020

Nilai cronbach alpha merupakan nilai yang menggabarkan apakah sebuah penelitian tersebut dapat dikatakab reliabel atau tidak. Nilai cronbach alpha dari sebuah penelitian tidak boleh lebih besar dari 0,600. Bedasarkan tabel 3, tampak nilai cronbach alpha dari tiap variabelnya melebihi nilai 0,600 . Sehingga dapat dikatakan bahwa ketiga variabel ini memenuhi syarat.

\section{Uji Hipotesis}

Pengujian analisis regersi berganda dilakukan untuk melihat bagaimana pengaruh pengetahuan investasi pasar modal dan return terhadap minat investasi pasar modal dikalangan mahaiswa. Pada uji ini, pengetahuan investasi pasar modal dan return berperan sebagai variabel independen dan minat investasi berperan sebagai variabel dependen. Berdasarkan analsisi regersi berganda, maka didapatkan hasil sebagai berikut

Tabel 5. Hasil Uji Hipotesis

\begin{tabular}{lccc}
\hline & $\beta$ & $\alpha$ & Hasil \\
\hline $\begin{array}{l}\text { Pengetahuan investasi pasar modal berpengaruh } \\
\text { positif dan signifikan terjadap minat investasi } \\
\text { pasar modal di kalangan mahasiswa di Surakarta }\end{array}$ & 0,300 & 0,001 & Diterima \\
\hline $\begin{array}{l}\text { Return berpengaruh positif dan signifikan } \\
\text { terjadap minat investasi pasar modal di kalangan } \\
\text { mahasiswa di Surakarta }\end{array}$ & 0,443 & 0,000 & Diterima \\
\hline
\end{tabular}

Sumber: Data Primer diolah, 2021

Berdasarkan hasil pengujian hipotesis yang telah dilakukan, maka tampak bahwa pengetahuan investasi pasar modal memiliki pengaruh positif dan signifikan terhadap minat investasi dikalangan mahasiswa di Surakarta. Ini menujukkan bahwa hipotesis $\left(\mathrm{H}_{1}\right)$ dinyatakan diterima. Sama hal dengan variabel pengetahuan investasi pasar modal, return juga memiliki pengaruh positif dan signifikan terhadap minat investasi pasar modal dikalangan mahasiswa, yang berarti hipotesis $\left(\mathrm{H}_{2}\right)$ dinyatakan diterima.

\section{Koefisien Determinasi}

Pengujian selanjutnya adalah koefisien determinasi. Pada pengujian ini dilakukan untuk menentukan seberapa besar variabel pengetahuan investasi pasar modal dan return (variable independen) memepengaruhi variable minat investasi (variable dependen). Berdasarkan pengujian yang dilakukan, maka didapatkan hasil sebagai berikut: 
Tabel 6. Koefisien Determinasi

\begin{tabular}{cc}
\hline $\mathbf{R}$ & R Square \\
\hline 0,723 & 0,523 \\
\hline
\end{tabular}

Sumber: Data Primer diolah, 2021

Pada tabel 6, tampak bahwa besaran nilai koefisien determinasinya sebesar 0,523. Nilai ini menggambarkan bahwa pengetahuan investasi pasar modal dan return hanya berpengaruh sebesar $52,3 \%$ terhadap minat investasi. Selanjurnya sebesar $47,7 \%$ lainnya dipengaruhi oleh variablevariabel lain di luar penelitian.

\subsection{Pembahasan}

\section{Hubungan Pengetahuan Investasi Pasar Modal dengan Minat Investasi}

Berdasarkan hasil pengujian yang pada Tabel 2. tampak bahwa variabel pengetahuan investasi pasar modal terhadap variabel minat invetasi berpengaruh positif dan signifikan. Hal ini ditandai dengan nilai koefisien sebesar 0,001 , yang menandakan bahwa hipotesis $\left(\mathrm{H}_{1}\right)$ diterima

Pengetahuan investasi pasar modal yang berpengaruh signifikan terhadap minat invetasi mahasiswa, menjelaskan bahwa ketika mahasiswa telah mendapatkan pemahaman yang lebih dalam mengenai pasar modal, minat mereka untuk melakukan investasi pada pasar modal cenderung akan lebih kuat. Pengetahuan investasi pasar modal yang dimiliki mahasiswa menjadi dasar mereka untuk menentukan investasi pasar modal apa yang sesuai dengan kebutuhan mereka.

Wibowo (2019), mengemukakan bahwa minat investasi dipengaruhi oleh pengetahuan investasi. Pada penelitian tersebut menjelaskan bahwa minat investasi mahasiswa yang timbul dari adanya pengetahuan investasi pasar modal merupakan cerminan dari Theory Planned Behavior. Teori ini menjelaskan bahwa ketika seseorang memiliki minat untuk melakukan sesuatu, mereka akan cenderung melakukan berbagai cara untuk mencapai tujuannya. Sehingga bisa dikatakan bahwa ketika seseorang memahami lebih dalam mengenai pasar modal, maka mereka akan melakukan investasi. Dengan pemahaman pasar modal yang cukup, maka mereka dapat mengelola dengan baik investasi apa yang dapat mencapai tujuan mereka. Semakin mendalam pengetahuan investasi yang di miliki, maka semakin tinggi pulan minat berinvestasi.

\section{Hubungan Return dengan Minat Investasi}

Berdasarkan hasil pengujian yang pada Tabel 2. tampak bahwa variabel return terhadap variabel minat invetasi berpengaruh positif dan signifikan. Nilai koefisien sebesar 0,000 , menandakan bahwa Ho ditolak dan Ha diterima

Return berpengaruh signifikan terhadap minat invetasi. Hasil ini menjelaskan bahwa minat investasi mahasiswa pada pasar modal dikarenakan iming-iming dari besaran return yang didapatkan. Walaupun mahasiswa mengerti dengan konsekuesi risiko yang didapatkan ketika berinvestasi di pasar modal, mereka masih tetap berminat untuk berinvestasi dipasar modal.

Hidayat dan Supriadi (2019) juga menemukan bahwa pengetahuan mengenai return yang didapatkan berpengaruh signifikan terhadap minat investasi dikalangan mahaisiswa. 


\section{KESIMPULAN}

Penelitian ini menjelaskan mengenai bagaimana pengaruh variabel pengetahuan investasi pasar modal dan return terhadap terhadap minat invetasi mahasiswa di Surakarta. Dari peneitian ini dapat ditarik kesimpulan antara lain:

a. Pengetahuan investasi pasar modal berpengaruh signifikan terhadap minat invetasi mahasiswa. Sehingga dapat dikatakan bahwa semakin tinggi pengetahuan yang miliki mahasiswa terkait dengan pasar modal, maka semakin tinggi pula minat mahasiswa dalam berinvestasi.

b. Return berpengaruh signifikan terhadap minat investasi mahasiswa. Sehingga dapat dikatakan bahwa tingkat timbal balik atau return yang dihasilkan oleh mahasiswa menjadi faktor yang mendorong minat mahasiswa untuk berinvestasi di pasar modal

\section{DAFTAR PUSTAKA}

Devianti, L. P. A. E., Purnamawati, I. G. A., \& Yasa, I. N. P. (2017) "Pengaruh Norma Subjektif, Persepsi Return dan Literasi Keuangan Terhadap Minat Mahasiswa untuk Berinvestasi Saham di Pasar Modal", eJournal S1 Ak,

Doddy, M. \& Millah, Z. (2019). The Influence of Management Knowledge on The Interest of Student Investing in Peer to Peer Lending Shariah. Jurnal Ekonomi dan Perbankan Syariah Vol. 7. No.2.

Hidayat, L., Muktiadji, N., \& Supriadi, Y. (2019). Pengaruh Pengetahuan Investasi Terhadap Minat Mahasiswa Berinvestasi di Galeri Investasi Perguruan Tinggi. Jurnal Analisis Sistem Pendidikan Tinggi, Vol 3 No.2, $63-70$

KSEI News, Edisi 03 Juni - September 2020. “KSEI's Strategic Role in Increasing Capital Market Stability". Hal 4.

Latha, R. (2016), "Investors Behaviour Towards Investment Intention: A Study Of Investors Of Mutual Funds In Naapattinam District", International Journal of Innovative Research and Advanced Studies (IJIRAS), Vol. 3, Issue 9: 73-78.

Setyanataa, B. \& Kadiba, D. C.A. (2020). "The Effect of Perceived Ease of Use, Investment Knowledge, and Perceived Risk on Intentions to Purchase of Share of Generation Y". Andalas Management Review, Vol.4 No.2.

Susanto, H. (2012). Cerdas Memilih Investasi. Jakarta: PT Elex Media Komputindo

Tandelilin, E. (2010). Portofolio dan Investasi: Teori dan Aplikasi. Edisi 1. Kanisius. Yogyakarta.

Taufiqoh, E., Diana, N., \& Junaidi. (2019), "Pengaruh norma subjektif, motivasi investasi, pengetahuan investasi, persepsi return dan literasi keuangan terhadap minat mahasiswa berinvestasi saham di pasar modal (studi empiris pada Mahasiswa Akuntansi FEB UNISMA dan UNIBRAW di Malang)”, Jurnal Ilmiah Riset Akuntansi, Vo. 8, No. 5 : 9-19. Trisnation, Y. A. \& Pustikaningsih, A. (2017). The Influence Of Expectation Of Return, Perception Of Risk, And Self Efficacy Of Faculty Of Economic's Student At Yogyakarta 
State University Towards Their Interest To Investing Stocks. Jurnal Profita Kajian Ilmu Akuntansi Volume 6 No. 3.

Wibowo, A. (2019). "Pengaruh Pengetahuan Investasi, Kebijakan Modal Minimal Investasi, Dan Pelatihan Pasar Modal Terhadap Minat Investasi (Studi Kasus Mahasiswa Fe Unesa Yang Terdaftar Di Galeri Investasi Fe Unesa)" Jurnal Ilmu Manajemen Fakultas Ekonomi Universitas Negeri Surabaya Volume 7 No. 1 